\title{
MITOCHONDRIAL DNA ARRANGED INTO CHROMATIN-LIKE STRUCTURES AFTER INJECTION INTO AMPHIBIAN OOCYTE NUCLEI
}

\author{
HANSWALTER ZENTGRAF, ${ }^{1}$ MICHAEL F. TRENDELENBURG,${ }^{1}$ HERBERT SPRING, ${ }^{t}$ \\ ULRICH SCHEER, ${ }^{1}$ WERNER W. FRANKE, ${ }^{1}$ ULRIKE MÜLLER, ${ }^{2}$ \\ KENNETH C. DRURY ${ }^{3}$ and DURI RUNGGER ${ }^{3}$
}

\author{
'Institute for Virus Research and Division of Membrane Biology and Biochemistry, Institute for \\ Experimental Pathology, German Cancer Research Center, D-6900 Heidelberg, \\ ${ }^{2}$ Department of Microbiology, University of Heidelberg, D-6900 Heidelberg, Germany, \\ and ${ }^{3}$ Department of Animal Biology, University of Geneva, CH-1224 Chêne-Bougeries, Switzerland
}

\begin{abstract}
SUMMARY
Purified mitochondrial DNA (mitDNA) from ovaries of Xenopus laevis was injected into the nuclei (germinal vesicles) of large vitellogenic oocytes of the same organism and examined by electron microscopy of the spread nuclear contents. Normally located nuclei of untreated oocytes as well as peripherally translocated nuclei of centrifuged oocytes were used. In addition, oocyte nuclei isolated and incubated under liquid paraffin oil were injected with DNA. The integrity of transcriptional structures of endogenous chromosomal (lampbrush chromosomes) and extrachromosomal (nucleoli) genes of the injected nuclei was demonstrated. Microinjected mitDNA was identified as circles of chromatin exhibiting polynucleosome-like organization and a mean contour length of 2.6 $\mu \mathrm{m}$, corresponding to a compaction ratio of the mitDNA of about $2: 1$. This DNA packing ratio is similar to that observed after preparation of various kinds of native chromatin in low salt buffers. The chromatin circles formed from injected mitDNA only very rarely exhibited lateral fibrils suggestive of transcriptional activity. These results suggest that purified mitDNA can be transformed to normally structured chromatin when exposed to oocyte nuclear contents but is rarely, if at all, transcribed in this form and in this environment.
\end{abstract}

Circular double-stranded DNA molecules injected into oocyte nuclei of Xenopus laevis are relatively stable and can be assembled into chromatin-like configurations. This has been demonstrated for SV40 DNA [1-5], plasmid DNA [6] and extrachromosomal ribosomal DNA (rDNA) from an insect [7]. Moreover, transcription of genes contained in such injected DNA molecules has been demonstrated [8], e.g., for SV40 DNA [9-13], and for various plasmids such as those containing genes coding for histones of Drosophila $[9,11]$ or sea urchin [14-16], genes coding for 5S rRNA of Xeno- pus [17], genes coding for tRNAs of a nematode [18] or Xenopus laevis [15, 19], and a plasmid containing a major portion of the pre-rRNA gene of Xenopus [6]. Transcription of DNA injected into Xenopus oocyte nuclei has also been demonstrated for the naturally occurring circular pre-rRNA genes from ovaries of the water beetle, Dytiscus marginalis [7]. In the present study we show that another eukaryotic kind of circular DNA, which in nature is not associated with histones and nuclear transcriptional complexes, namely the mitochondrial genome, can be organized into 
nucleosome-like chromatin structures upon microinjection into the amphibian oocyte nucleus.

\section{MATERIALS AND METHODS}

\section{Isolation of DNA}

Mitochondrial DNA (mitDNA) was prepared from isolated mitochondria of Xenopus laevis ovaries as described by Dawid [20]. The DNA was extracted by digestion with pronase $(0.5 \mathrm{mg} / \mathrm{ml})$ in the presence of $2 \%$ Sarkosyl NL 97 and $50 \mathrm{mM}$ Tris- $\mathrm{HCl}$ buffer $(\mathrm{pH}$ 7.2) for $12 \mathrm{~h}$ at $37^{\circ} \mathrm{C}$, followed by shaking twice with phenol and chloroform/isoamylalcohol (24:1), respectively. The material was dialysed against buffer (10 mM Tris- $\mathrm{HCl}, \mathrm{pH} 7.2 ; 1 \mathrm{mM}$ EDTA), adjusted to an initial density of $1.702 \mathrm{~g} / \mathrm{cm}^{3}$ by the addition of $\mathrm{CsCl}$ and run for $60 \mathrm{~h}$ at $20^{\circ} \mathrm{C}$ at $40000 \mathrm{rpm}$ in the $50 \mathrm{Ti}$ rotor of a Beckman-Spinco ultracentrifuge.

Simian virus (SV40) DNA was prepared from subconfluent CV1 cells (African green monkey cell line CV1) in roller bottles infected at a multiplicity of approx. $10 \mathrm{pfu} /$ cell with plaque-purified SV40 strain 777. Virus was allowed to adsorb at $37^{\circ} \mathrm{C}$ for $1 \mathrm{~h}$, and $100 \mathrm{ml}$ of culture medium containing $2 \%$ fetal calf serum (FCS) were then added to each roller bottle. The infection was allowed to proceed for $70 \mathrm{~h}$. Cells were harvested and viral and cellular DNA were separated by precipitation of the cellular DNA according to the procedure described by Hirt [21]. The supernatant fluid was extracted three times with phenol, precipitated with ethanol, dialysed against buffer $(10 \mathrm{mM}$ Tris- $\mathrm{HCl}, \mathrm{pH} 7.2 ; 1 \mathrm{mM}$ EDTA; $0.2 \mathrm{M} \mathrm{NaCl}$ ) and run twice in $\mathrm{CsCl}$ gradients to minimize RNA contamination.

\section{Injection experiments}

Mitochondrial DNA or SV40 DNA was injected into nuclei of intact large Xenopus laevis oocytes (stage V and VI sensu [22]) or into manually isolated nuclei of these stages. Alternatively, one of the following injection procedures was employed.

(a) Oocytes were injected with 1-2 ng DNA dissolved in $10-15 \mathrm{nl}$ injection buffer $(15 \mathrm{mM}$ Tris- $\mathrm{HCl}$, $\mathrm{pH} 7.6 ; 88 \mathrm{mM} \mathrm{NaCl}, 1 \mathrm{mM} \mathrm{KCl}$; $\mathrm{cf}$ [23]), aimed for the oocyte nuclei, and incubated for one day. This injection procedure has been described in detail [24]. The oocyte nuclei were then manually isolated and their contents spread for electron microscopy as described [7].

(b) The second injection technique used included a centrifugation step in order to facilitate nuclear injection [19] and has been described elsewhere [13]. In order to defolliculate the oocytes small pieces excised from the ovary were first incubated in OR2 medium without $\mathrm{Ca}^{2+}$ ions $[25,26]$ containing $0.2 \%$ collagenase [26], at $\max .27^{\circ} \mathrm{C}$ with gentle agitation for $2 \mathrm{~h}$. Separated oocytes were selected, transferred to normal Barth's solution [27] and incubated for $1 \mathrm{~h}$. Centrifugation of the isolated oocytes was performed as described [19]. Injection of the oocyte nuclei, incubation ( $3 \mathrm{~h}$ or 1 day) and spreading for electron microscopy was as described [ $\mathrm{cf} 7,13]$.

(c) Oocytes were manually isolated from ovaries in Barth's solution and washed twice in " $5: 1 "$ "-medium [28]. After careful removal of the washing medium the oocytes were covered with paraffin oil (Merck, Darmstadt, FRG). The oocyte nucleus was isolated under oil, cleaned from the adhering ooplasm and transferred into an oil drop put onto a siliconized glass slide. After injection of the DNA samples (as described above) the slides were kept at $20^{\circ} \mathrm{C}$ for $3-5$ $\mathrm{h}$ and processed for electron microscopy as described (see below).

\section{Spreading procedures}

Deproteinized DNA was prepared for electron microscopy by the cytochrome $c$ droplet diffusion method [29] and stained and shadowed as described [30].

Nuclear contents were allowed to disperse under very low salt conditions $(0.1 \mathrm{mM}$ sodium borate buffer, $\mathrm{pH} 8.0$ or 9.0; $\mathrm{cf}[31]$ ), centrifuged, stained and shadow-cast as described [7, 31-33].

\section{Electron microscopy}

Micrographs were taken with a Zeiss EM-10 electron microscope at 40 or $60 \mathrm{kV}$. The magnification indicator was routinely controlled by comparison with a grating replica. Length measurements of DNA molecules or chromatin units, calculations and distribution analyses were performed as described [30].

\section{RESULTS}

\section{Preservation of endogenous chromatin structures during and after injection}

In experiments on the organization and transcription of DNA injected into am-

Fig. 1. Survey electron micrograph of spread lampbrush chromosome material from Xenopus laevis oocyte nucleus isolated under liquid paraffin oil, injected with SV40 DNA, and incubated for $3 \mathrm{~h}$ under oil. The lampbrush chromosome shows normal ultrastructure with loops containing active transcriptional units relatively densely covered with lateral fibrils. Note that transcriptional units differ in sizes (the two short arrows in the bottom part denote very small units), in their polarity within the loop (indicated, e.g., by the arrows in two loops in the upper part), and in patterns of interspersed, apparently non-transcribed intercepts ('spacers'; see most of the loops; the vertical bar indicates a situation in which a transcriptional unit seems to be closely followed by another matrix unit, without visible spacer intercept). For description of types of transcriptional units in lampbrush chromosomes see ref. [66]. Bar, $10 \mu \mathrm{m}$. $\times 4400$. 


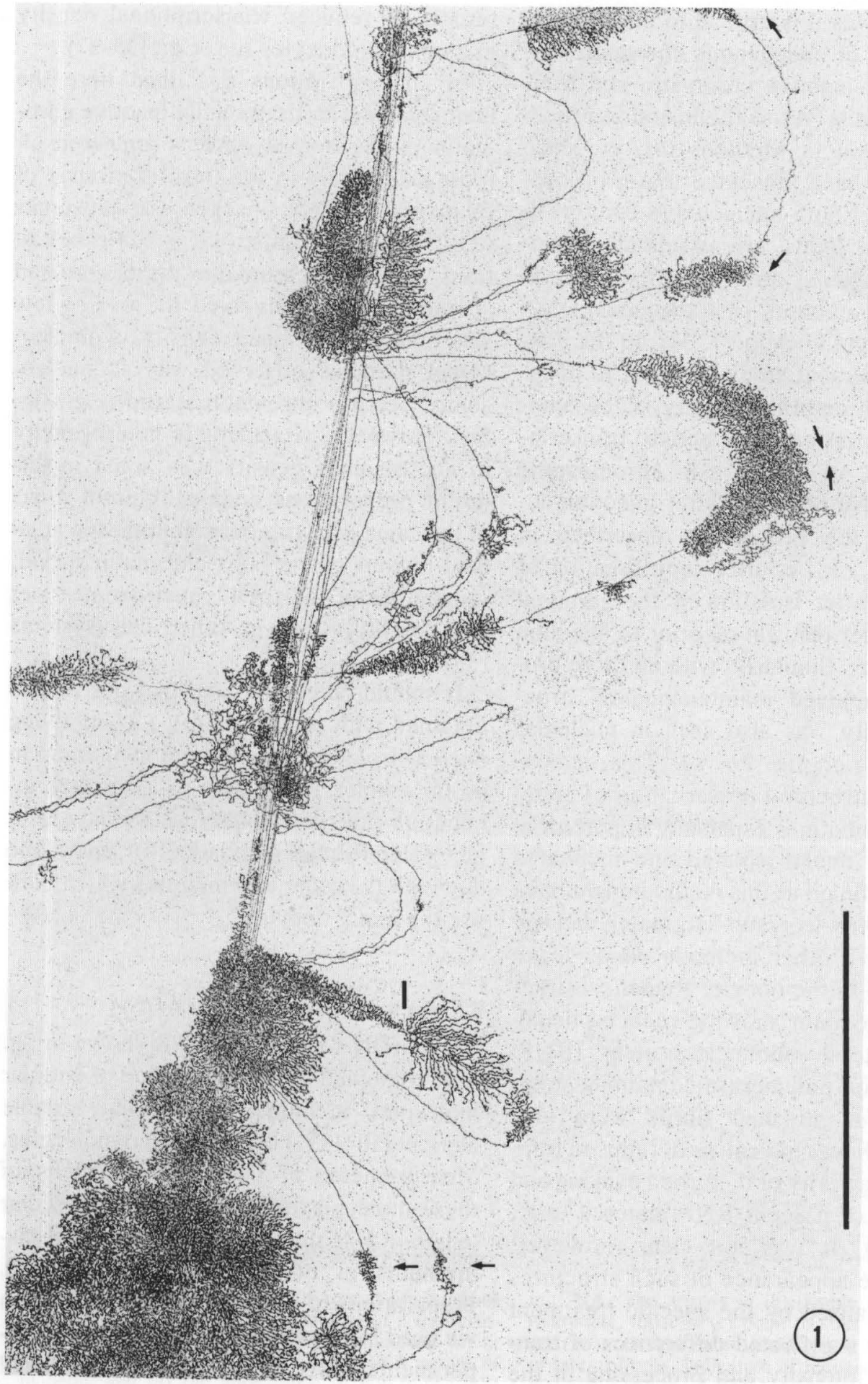


phibian oocytes it is critical to monitor the preservation of endogenous chromatin, including both inactive chromatin and transcriptional units. As to the injection procedure described in Methods (a), evidence has recently been presented that transcriptional units of both nucleoli and lampbrush chromosome loops are essentially unaffected during and after injection of relatively large amounts of exogenous DNA into the oocyte nucleus $[7,34]$. In the context of the present study we want to document that structural integrity of chromosome organization and active transcriptional units of lampbrush chromosome loops was also observed after injection according to the procedures described in Methods $(b, c)$, i.e. after centrifugation of oocytes or after isolation of the germinal vesicles under paraffin oil prior to injection (figs $1,2 a-d$ ). Similarly, with all three procedures employed maintenance of structural integrity was also seen in nucleolar structures (e.g., fig. $2 b, c)$. This demonstration of structural preservation of endogenous chromatin is especially important in the case of nuclei isolated and incubated under paraffin oil as this method might have been expected to result in greater damage than the two other methods which leave the nucleus in the oocyte. Regions in transcribed chromatin showing reduced densities of lateral ribonucleoprotein (RNP) fibrils and/or polymerase-containing granules without attached fibrils were also found which was indicative of reduced transcriptional activity or disturbed packing and processing of nascent RNP material (e.g., fig. $2 b, c)$. It was not clear, however, whether the appearance of such structures had been caused by the specific treatment or whether it reflected differences of transcriptional intensity and processing in the specific oocyte used (for structures charac- teristic of reduced transcriptional density in amphibian oocytes see, e.g., [35-37].

In all preparations described here the endogenous transcriptionally inactive chromatin of the oocyte nucleus appeared almost exclusively in the form of strands of relatively closely packed nucleosomes (e.g., fig. 2d). Under the specific conditions used for chromatin dispersion and spreading, which involved the use of low salt buffers, the mean density of nucleosomal particles observed was 42 nucleosomes per $\mu \mathrm{m}$ chromatin strand (e.g., fig. $2 d$ ). However, considerable heterogeneity in nucleosomes density was noted in different preparations and in different areas of the same preparation, sometimes in adjacent regions of the same chromatin strand, ranging from 24 to 47 nucleosomes per $\mu \mathrm{m}$ (cf [40] and, in other cell systems [38-43]).

It should be emphasized that our results obtained with procedure $(c)$, i.e. involving nuclear isolation transfer and incubation in an oil droplet, are limited to a maximal incubation time of $5 \mathrm{~h}$ whereas we have usually extended the incubation for up to one day with the other two methods which both use the intact oocyte.

\section{Characterization of injected DNA}

The mitDNA as we used it is shown in fig. 3. It contained a high proportion of circular molecules, including a somewhat variable amount (10-18\%) of supercoiled molecules. Measurements of the contour lengths of these molecules showed a mean molecular length of $5.41 \mu \mathrm{m}$, similar to previous measurements of other authors [e.g. 44-47]. Preparations of purified SV40 DNA, which we used for comparison in our injection experiments, have been described in detail elsewhere [48-50]. 


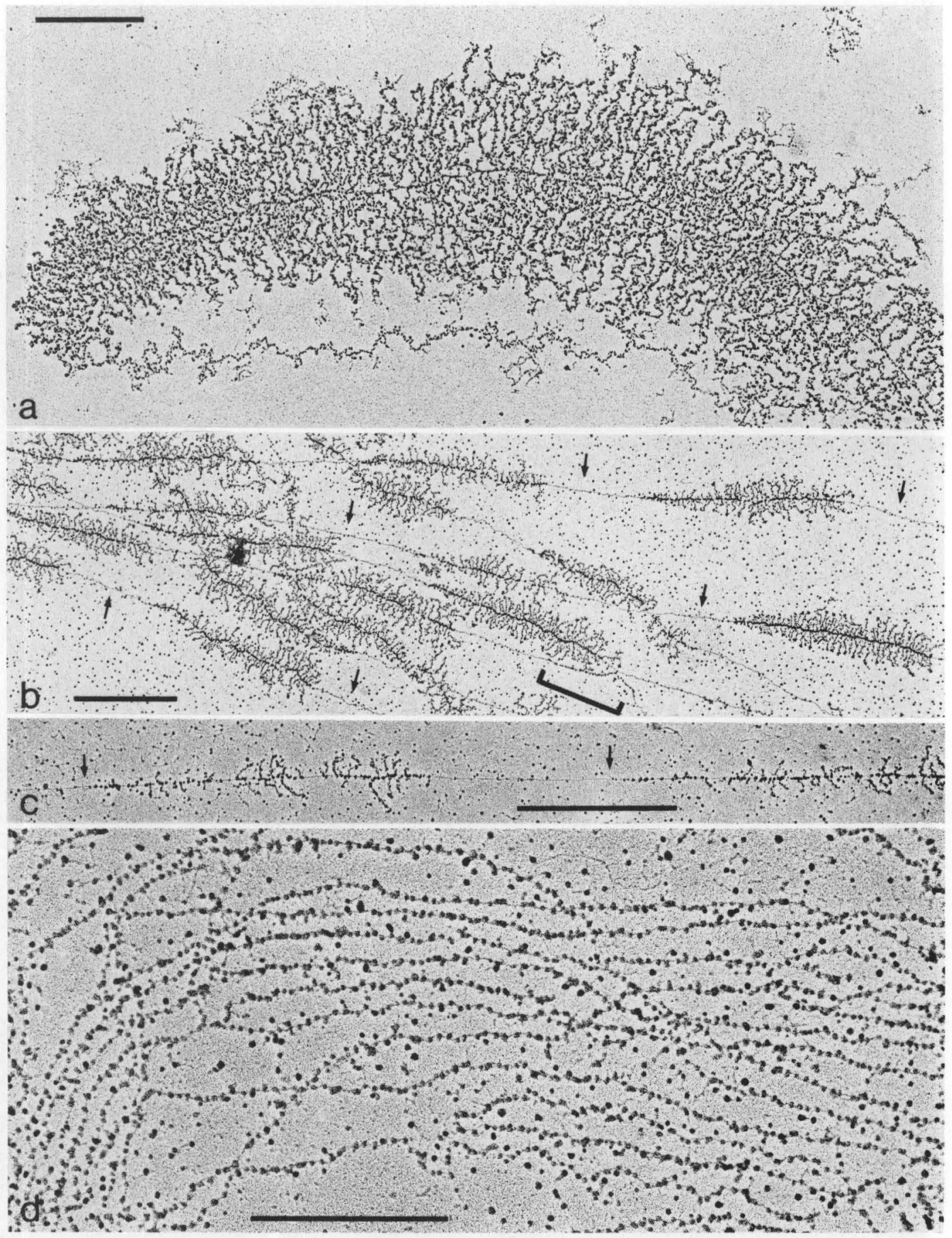

Fig. 2. Electron micrographs of spread preparations showing preservation of ultrastructure of a transcriptional unit of a lampbrush chromosome loop $(a)$ at higher magnification; $(b, c)$ in pre-rRNA genes of nucleoli; and $(d)$ the appearance of non-transcribed chromatin, either in oocyte nuclei of Xenopus laevis isolated $(a)$ under paraffin oil or $(b-d)$ in oocytes which have been centrifuged, injected with DNA samples, and incubated for $3 \mathrm{~h}$ (see Materials and Methods). DNA used for injections in the examples shown here has been $(a, b, d)$ SV40 DNA and $(c)$ Xenopus
mitDNA. The arrows in (b) denote apparent spacer intercepts, those in $(c)$ point to start regions of some matrix units that show significantly reduced density of lateral fibrils, indicative of reduced transcriptional activity. Lengths of rDNA matrix units and apparent spacer intercepts are in the normal range reported for this species [ $\mathrm{cf} 40,51]$. The bracket in $(b)$ denotes a region corresponding to a pre-rRNA gene which is associated with RNA polymerase-like granules but devoid of lateral fibrils. Bars: $(a-c) 1 \mu \mathrm{m} ;(d) 0.5 \mu \mathrm{m}$. (a) $\times 16000 ;(b) \times 15000 ;(c) \times 23000 ;(d) \times 58000$. 

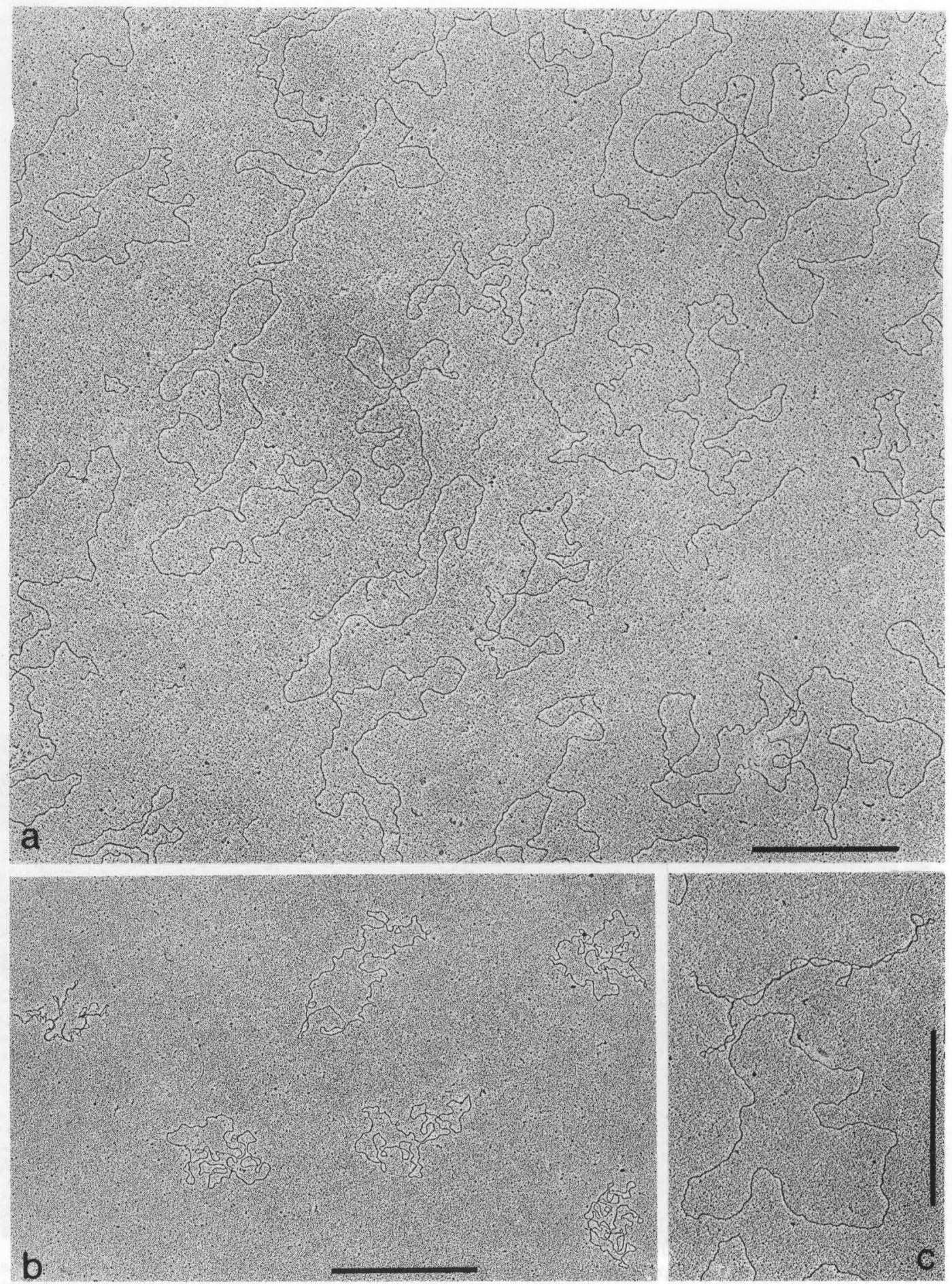

Fig. 3. Cytochrome $c$-spread preparation of isolated and purified DNA of mitochondria from Xenopus laevis ovaries used for the microinjection experiments. (a) Fraction of predominantly 'relaxed' circles illustrating the purity of the preparation; $(b)$ preparation of less extended circular molecules and the occurrence of supercoiled molecules (left) in a proportion of 10 $18 \%$ of circles; $(c)$ at higher magnification, the direct comparison of the supercoiled and the relaxed and extended configuration. Bar, $1 \mu \mathrm{m}$. $(a, b) \times 21000 ;(c)$ $\times 25500$. 


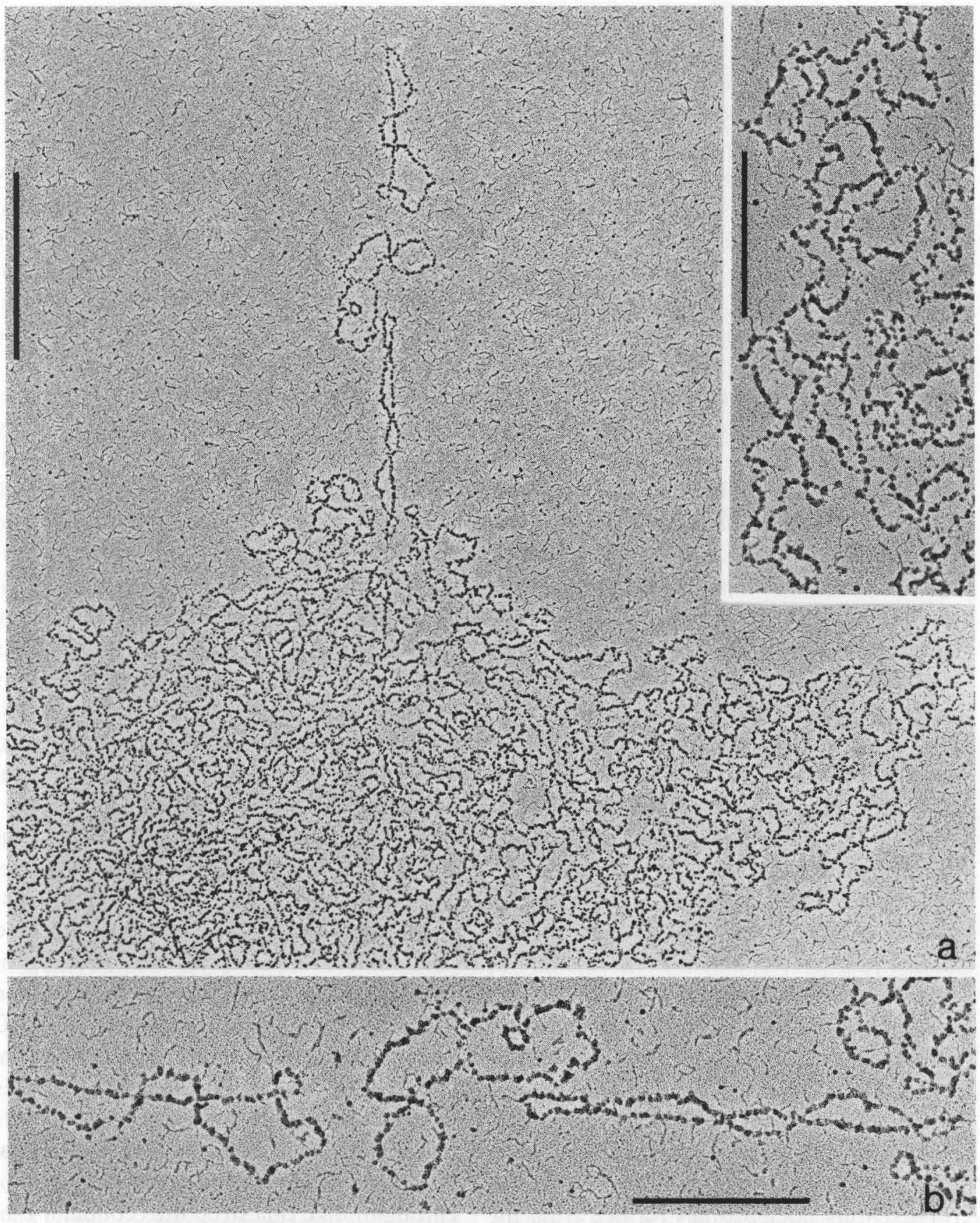

Fig. 4. Electron microscopy of spread preparations of large aggregates of rings of chromatin-like structures containing mitDNA of Xenopus laevis injected into oocyte nuclei of frogs of the same species. In the preparation shown here the oocytes have been centrifuged and treated as described in Methods $(b)$. Often the individual rings contained in such aggregates are identified only at higher magnification (inset in $a$ ). The 'beads-on-a-string' organization of the chromatin rings containing mitDNA is clearly recognized in $(b)$. The background in this preparation shows a finely threadlike pattern, probably artefactual structures, which have sometimes been observed in spread preparations of contents of injected oocyte nuclei. Bars: (a) $1 \mu \mathrm{m}$; (inset, $a, b) 0.5 \mu \mathrm{m},(a) \times 26000$; (inset) $\times 47000 ;(b)$ $\times 50000$. 


\section{Identification of mitDNA-containing structures in nuclei}

When contents of oocyte nuclei injected with mitDNA were dispersed in low salt buffers and spread for electron microscopy, numerous characteristic and rather homogeneously sized ring structures were found which we have never observed in uninjected nuclei and in nuclei injected with other kinds of DNA such as from SV40 and rDNA from Dytiscus ovaries (cf [7, 33, 51]; compare also fig. 5e). Therefore, and from the size distribution of these ring structures (see below), we conclude that these ring structures contain the injected circular DNA molecules. Frequently, these rings of chromatin-like morphology were seen in large aggregates, some of which contained several hundred rings (fig. $4 a$ ). Each of these rings appeared as a chain of beads of diameter 10-13 $\mathrm{nm}$ (figs 4, 5), with center-to-center distances, in rings of relatively dense bead packing, of $20-23 \mathrm{~nm}$. However, regions with greater bead-tobead distances were also found in some rings (fig. 5; in particular, see inset in fig. $5 a$ and fig. $5 d$ ). The morphology of the rings was indistinguishable from that of inactive chromatin endogenous to the injected nuclei (fig. $2 d$; $\mathrm{cf}[52]$ ) and was also similar to that of inactive chromatin observed in a diversity of other cells (for refs see $[39,41-43,52-54])$, including non-transcribed chromatin formed from plasmid or SV40 DNA injected to Xenopus laevis oocyte nuclei (cf fig. $5 e ;[3,6]$ ). Therefore, we interpret these beads seen in association with mitDNA injected into the nucleus as representing nucleosomes formed from the large reservoir of stored histones present in Xenopus oocytes [3-5; cf 55].

When numbers of nucleosome-sized beads per ring of mitDNA were counted a mean value of 86 and a maximum of 94 beads/ring was determined (in such evaluations we did not include rings revealing larger 'gaps' in bead density as, for example, the ring shown in the insert of fig. $5 a$ ). Rings of chromatin-like bead structures formed in association with SV40 DNA injected in parallel were counted to contain a maximum of 26 and a mean of 24 particles (cf fig. $5 e$ ), i.e. a value similar to nucleosomal numbers of SV40 'minichromosomes' in infected somatic cells grown in culture [48-50, 56-58].

We also repeatedly observed less intensely stained fibril structures characterized by a homogeneously 'smooth', i.e. non-beaded, contour and a diameter of 7-12 nm which sometimes showed continuity with the beaded chromatin-like fibrils of rings containing the injected mitDNA (fig. $5 c$ ). Similar non-beaded thread-like structures were also seen in linear forms, i.e. with free ends (fig. $5 c$ ). We do not know the nature of this unusual structure but the continuity with arrays of chromatinous 'beads-on-a-string' fibrils may suggest that this is another form of deoxyribonucleoprotein complex.

Since transcriptional activity of DNA injected into Xenopus laevis oocyte nuclei had been demonstrated by electron microscopy $[6,7]$, and transcription of injected DNA has been shown for various kinds of DNA containing promoters of transcription for nuclear RNA polymerases A, B and C (for references see p. 363) we paid special attention to the identification of structures possibly related to transcriptional events that might be indicated by arrays of lateral fibrils. However, in the many hundreds of chromatin-like ring structures containing injected mitDNA only few configurations suggestive of lateral fibril formation were encountered (e.g., fig. $5 d$ ). Moreover, the number of such lateral fibril structures/ circle was never greater than two. Mostly, 

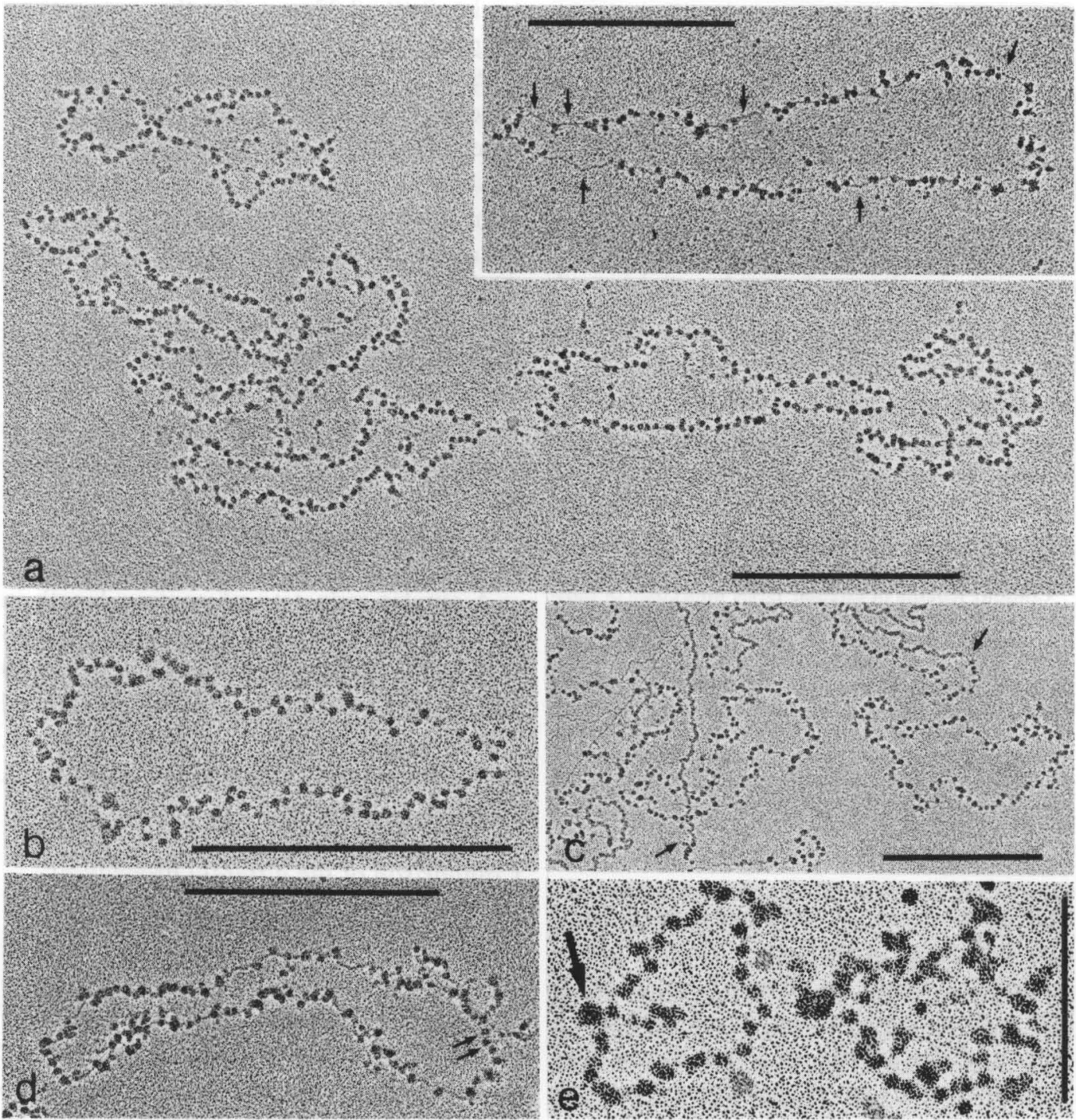

Fig. 5. Details of the morphology of chromatin-like circular structures observed in spread preparations of contents of oocyte nuclei of Xenopus laevis injected with $(a-d)$ mitDNA or (e) SV40 DNA. Preparations shown in $(a-d)$ are from nuclei injected as described in Methods $(a)$, that shown in $(e)$ has been injected as described in Methods $(b)$. Note the dense packing of nucleosome-like granules in most of the rings containing the injected DNA $(a, b)$; the inset in $(a)$ presents an example of a ring showing some relatively extended intergranular regions of thin and smooth fibril character, possibly 'naked' DNA. Another structure sometimes observed in chromatin rings containing the injected mitDNA molecules (arrows in $c$ ) is character-

ized by a non-beaded, uniformly thick (7-12 nm) appearance. This structure is significantly less stained compared with the nucleosome-like chromatin beads. Only occasionally, one sees rings of chromatin-like morphology and of contour lengths typical of mitDNAcontaining chromatin which appear to be associated with lateral fibrils (arrows in $d$ ). Such structures may represent, but do not prove, the occurrence of transcriptional events. A similar situation is sometimes observed in rings of SV40 DNA-containing chromatin (e) which can exhibit a lateral fibril (arrow in $e$ ) attached to a relatively thick basal granule (arrow in $e$ ). Bars: $(a-d) 0.5 \mu \mathrm{m}$; (e) $0.2 \mu \mathrm{m}$. (a) $\times 57000$; inset, $\times 53000$; (b) $\times 83500 ;(c) \times 42500 ;(d) \times 66000 ;(e) \times 128000$. 


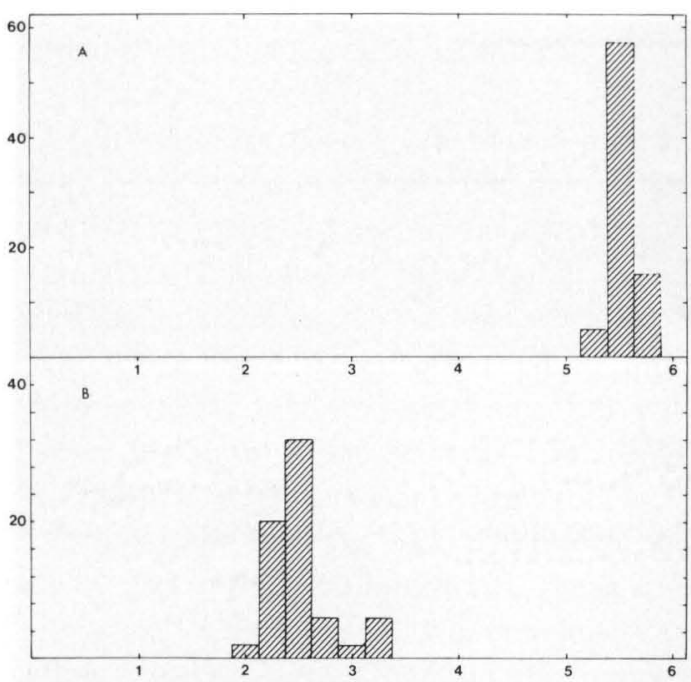

Fig. 6. Abscissa: contour length (nm); ordinate: no. of measurements.

Contour lengths of circular DNA molecules of purified mitDNA from Xenopus laevis ovaries, as used for injection $(A)$, in comparison with the contour lengths of the rings of chromatin-like structures observed in spread preparations, in low salt buffers, of contents of oocyte nuclei of Xenopus laevis injected with the mitDNA presented above $(B)$. Only circular chromatin structures longer than $1.5 \mu \mathrm{m}$ have been included. The data suggest a reduction of the contour length of the mitDNA indicative of a compaction of about 2 -fold.

such rings exhibited only one lateral fibrillike structure. Interestingly, rings of chromatin assembled on injected SV40 DNA also very rarely showed lateral fibril structures and those rings, in which lateral fibril structures were seen, usually did contain not more than one such lateral fibril (e.g., fig. $5 e$ ).

\section{Comparison of contour length of} mitDNA with those containing of chromatin circles mitDNA

Fig. 5 presents the histograms of purified mitDNA (a) and of the chromatin-like rings formed in oocyte nuclei injected with mitDNA $(b)$. The mean contour length of the class of beaded chromatin-like rings containing the injected mitDNA was estimated to be $2.68 \pm 0.32 \mu \mathrm{m}$ (in the preparation prepared as described in Methods $(a))$ and $2.56 \pm 0.24 \mu \mathrm{m}$ (in preparations according to procedure outlined in Methods $(b)$; values determined in preparations made as described in Methods $(c)$ are similar but the total number of measurements was too small for reasonable statistical evaluation). These values correspond to mean compaction rations of the mitDNA of $2.02: 1$ and $2.11: 1$, respectively. Since in the same preparations a few circles of contour lengths of about $2.0 \mu \mathrm{m}$ were also found it might be concluded that the maximal packing ratio of mitDNA observed under the low ionic strength conditions employed can be ca $2.7: 1$.

A similar reduction of contour length in the chromatin formed upon injection into the oocyte nuclei was observed in the SV40 DNA molecules (cf fig. $5 e$ ) which showed a mean contour length of $0.76 \pm 0.21 \mu \mathrm{m}$, indicating a compaction of the SV40 DNA of approx. 2-fold [cf 56].

\section{Comparison of the different procedures} used for injection

Similar results have been obtained with all three methods used. While the procedure described in Methods $(c)$ has the advantage of excluding cytoplasmic contributions during and after injection, the other two methods allow much longer incubation times and seem to be more physiological.

\section{DISCUSSION}

Our results show that mitDNA injected into a nucleus, i.e. the germinal vesicle of Xenopus laevis oocytes, is relatively stable and is efficiently assembled into chromatin structures revealing a nucleosome-like organization. These observations confirm and extend those made with other circular forms 
of DNA injected into oocyte nuclei such as SV40 DNA ([3-5, 10]; this study) and plasmid DNA [6]. The compaction ratio of the injected mitDNA in the chromatin rings formed is similar to that observed, at low salt concentrations, in other circular DNA molecules such as amplified rDNA present in non-transcribed nucleolar chromatin of oocytes of the water beetle, Dytiscus marginalis [42], and the chromatin rings containing DNAs of some viruses such as SV40 ([48-50, 56-60]; as to injection experiments see also [3-5]) and human and bovine papilloma viruses [61]. Assuming a total of approx. 17000 base pairs per mitochondrial genome (for basis of estimation $\mathrm{cf}$ [62]) the observed mean value of 86 nucleosomes and the maximum of 94 nucleosomes per assembled mitochondrial chromatin rings would correspond to nucleosomal contents of 198 and 181 base pairs of DNA, respectively, which is close to the figure of 185 base pairs of DNA per nucleosome reported for chromatin of oocytes of Xenopus laevis [40].

Most of the chromatin rings formed from injected circular molecules of mitDNA appear to be transcriptionally inactive and tend to form large aggregates. Our results, in particular the observed absence of lateral fibril structures in most mitDNA-containing chromatin rings, indicate that the great majority of the injected molecules are not transcribed. Low proportions of transcribed DNA molecules have also been found when plasmid molecules containing parts of the pre-rRNA gene have been injected into Xenopus oocyte nuclei [6]. Similarly, we have seen only very few SV40 'minichromosomes' with sizeable lateral fibrils attached when SV40 DNA has been injected into oocyte nuclei (this study; compare also [3]). On the other hand, it has been demonstrated that some injected DNA molecules can be correctly transcribed, including SV40 DNA (for refs see p. 363). Thus, our present data do not allow a conclusion as to the problem of possible proper and/or erratic transcription of the injected mitDNA. The few lateral fibril structures found in some of the chromatin rings containing injected mitDNA might well reflect occasional transcriptional events. However, clarification of this problem will have to await future biochemical experiments involving molecular hybridization techniques and/or coupled transcription-translation assays [cf 4, 9-19]. In this connection it should also be noted that lateral fibrils containing nascent transcripts usually are relatively sparse in SV40 chromatin rings in infected cells (e.g., [63]; P. Oudet \& P. Chambon, personal communication) as well as in many of the HeLa cell mitochondrial genomes seen in the spread preparations of Aloni \& Attardi [64]. At least, our demonstrations of maintained transcriptional activity of endogenous genes in the injected nuclei clearly indicate that the treatment of the oocyte and its nuclei per se is not harmful to transcription.

The chromatin-like arrangement of mitDNA injected into the nucleus as reported in this study is clearly different from the structures described by Pinon et al. [47] which have been interpreted as showing the native chromatin-like organization of protein complexes associated with the genome of mitochondria of Xenopus laevis oocytes (for another type of a single granular protein complex attached to the DNA of HeLa mitochondria see [65]). Pinon et al. [47] have presented a relatively protein-rich structure (1:1 w/w protein/DNA) consisting of an apparently relaxed circle (mean contour length $1.54 \mu \mathrm{m}$ ) of a chain of $48 \pm 4$ beads of nearly nucleosomal size. This would represent an apparent foreshortening 
of the mitDNA by a factor of about 3.4. It is obvious that this structure cannot represent a nucleosome-like organization of the whole mitochondrial genome since it would correspond to an equivalent of about 350 base pairs of DNA per bead. Thus the nature and the significance of the beaded arrays described by these authors will have to be further elucidated before a detailed comparison with intranuclear chromatin structures can be made.

MitDNA assembled into circular chromatin upon injection into the nucleus is also an interesting model for studies of chromatin organization since the size of the molecule by far exceeds that of the only well studied model, the SV40 chromatin, by a factor of about 3.6. This would make the 'mitochondrial minichromosome' an attractive object in studies of, for example, changes of superhelicity and other conformational questions.

This work has been supported in parts by the Deutsche Forschungsgemeinschaft (incl. a stipendium awarded to M. F. T) and the Swiss National Foundation (grant 3300.0 .78 ). We thank Dr J. B. Gurdon (MRC Laboratory of Molecular Biology, Cambridge, UK) for helpful discussions and advice.

\section{REFERENCES}

1. Wyllie, A H, Gurdon, J B \& Price, J, Nature 268 (1977) 152.

2. Laskey, R A, Mills, A D \& Morris, N R, Cell 10 (1977) 237.

3. Wyllie, A H, Laskey, R A, Finch, J \& Gurdon, J B, Dev biol 64 (1978) 178.

4. Laskey, R A, Honda, B M, Mills, A D, Morris, N R, Wyllie, A H, Mertz, J E, De Robertis, E M \& Gurdon, J B, Cold Spring Harbor symp quant biol 42 (1978) 171.

5. Laskey, R A, Honda, B M, Mills, A D \& Finch, J T, Nature 275 (1978) 416.

6. Trendelenburg, M F \& Gurdon, J B, Nature 276 (1978) 292.

7. Trendelenburg, M F, Zentgraf, H, Franke, W W \& Gurdon, J B, Proc natl acad sci US 75 (1978) 3791.

8. Colman, A, Eur j biochem 57 (1975) 85.

9. Mertz, J E \& Gurdon, J B, Proc natl acad sci US 74 (1977) 1502.

10. Gurdon, J B, De Robertis, E M, Partington, G A, Mertz, J E \& Laskey, R A, International cell biology (ed B R Brinkley \& K R Porter) p. 439. Rockefeller University Press, New York (1977).

11. De Robertis, E M \& Mertz, J E, Cell 12 (1977) 175.

12. Gurdon, J B, Wyllie, A H \& De Robertis, E M, Phil trans roy soc Lond b 283 (1978) 367.

13. Rungger, D \& Türler, H, Proc natl acad sci US 75 (1978) 6073.

14. Birnstiel, M L, Kressmann, A, Schaffner, W, Portmann, R \& Busslinger, M, Phil trans roy soc Lond b 283 (1978) 319.

15. Etkin, L D, Am zool 18 (1978) 215.

16. Kressmann, A, Clarkson, S G, Pirrotta, V \& Birnstiel, M L, Proc natl acad sci US 75 (1978) 1176.

17. Brown, D D \& Gurdon, J B, Proc natl acad sci US 74 (1977) 2064.

18. Melton, D A, Cortese, R, De Robertis, E M, Trendelenburg, M F \& Gurdon, J B, Results and problems in cell differentiation (ed W Beermann, W J Gehring, J B Gurdon, F C Kafatos \& J Reinert). Springer Verlag, Berlin, Heidelberg \& New York (1979). In press.

19. Kressmann, A, Clarkson, S G, Telford, J L \& Birnstiel, M L, Cold Spring Harbor symp quant biol 42 (1978) 1077.

20. Dawid, I B, Proc natl acad sci US 56 (1966) 269.

21. Hirt, B, J mol biol 26 (1967) 365.

22. Dumont, J N, J morphol 136 (1972) 153.

23. Gurdon, J B, Lane, C D, Woodland, H R \& Marbaix, G, Nature 233 (1971) 177.

24. Gurdon, J B, J embryol exp morphol 36 (1976) 513.

25. Wallace, R A, Jared, D W, Dumont, J N \& Sega, M W, J exp zool 184 (1973) 231.

26. Eppig, J J \& Dumont, J N, In vitro 12 (1976) 418.

27. Gurdon, J B, J embryol exp morphol 20 (1968) 401.

28. Callan, H G \& Lloyd, L, Phil trans roy soc Lond b 243b (1960) 135.

29. Lang, D \& Mitani, M, Biopolymers 9 (1970) 373.

30. Trendelenburg, M F, Scheer, U, Zentgraf, H \& Franke, W W, J mol biol 108 (1976) 453.

31. Miller, O L \& Bakken, A H, Acta endocrinol, suppl. 168 (1972) 155.

32. Miller, O L \& Beatty, B R, Genetics, suppl. 61 (1969) 133.

33. Scheer, U, Trendelenburg, M F \& Franke, W W, Exp cell res 80 (1973) 175.

34. Laskey, R A, Gurdon, J B \& Trendelenburg, M F, Symp soc exp biol (1979). In press.

35. Scheer, U, Trendelenburg, M F \& Franke, W W, J cell biol 65 (1975) 163 .

36. - Ibid 69 (1976) 465.

37. Rungger, D, Crippa, M, Trendelenburg, M F, Scheer, U \& Franke, W W, Exp cell res 116 (1978) 48.

38. Foe, V E, Wilkinson, L E \& Laird, C D, Cell 9 (1976) 131.

39. Foe, V E, Cold Spring Harbor symp quant biol 42 (1978) 723.

40. Reeder, R H, McKnight, S L \& Miller, O L, Cold Spring Harbor symp quant biol 42 (1978) 1174.

41. McKnight, S L, Bustin, M \& Miller, O L, Cold Spring Harbor symp quant biol 42 (1978) 741.

42. Scheer, U \& Zentgraf, H, Chromosoma 69 (1978) 243.

43. Franke, W W, Scheer, U, Zentgraf, H, Trendelen- 
burg, M F, Müller, U, Krohne, G \& Spring, H, Results and problems in cell differentiation (ed W Beerman, W J Gehrig, J Gurdon, F C Kafatos \& J Reinert). Springer Verlag, Berlin, Heidelberg \& New York (1979). In press.

44. Dawid, I B \& Wolstenholme, D R, J mol biol 28 (1967) 233.

45. Wolstenholme, D R \& Dawid, I B, Chromosoma 20 (1967) 445.

46. Borst, P \& Flavell, R A, Handbook of biochemistry and molecular biology (ed G D Fasman) 3rd edn, vol. 2, p. 363. CRC Press, Cleveland, Ohio, USA (1976).

47. Pinon, H, Barat, M, Tourte, M, Dufresne, C \& Mounolou, J C, Chromosoma 65 (1978) 383.

48. Keller, W, Müller, U, Eicken, I, Wendel, I \& Zentgraf, H, Cold Spring Harbor symp quant biol 42 (1978) 227.

49. Müller, U, Zentgraf, H, Eicken, I \& Keller, W, Science 20 (1978) 406.

50. Zentgraf, H, Keller, W \& Müller, U, Phil trans roy soc Lond b 283 (1978) 299.

51. Scheer, U, Trendelenburg, M F, Krohne, G \& Franke, W W, Chromosoma 60 (1977) 147.

52. Scheer, U, Cell 13 (1978) 353.

53. Franke, W W, Scheer, U, Trendelenburg, M F, Spring, H \& Zentgraf, H, Cytobiology 13 (1976) 401.

54. Franke, W W, Scheer, U, Trendelenburg, M F,
Zentgraf, H \& Spring, H, Cold Spring Harbor symp quant biol 42 (1978) 755 .

55. Woodland, H R \& Adamson, E D, Dev biol 57 (1977) 118.

56. Griffith, J D, Science 187 (1975) 1202.

57. Cremisi, C, Pignatti, P F, Croissant, O \& Yaniv, M, J virol 17 (1976) 204.

58. Oudet, P, Spadafora, C \& Chambon, P, Cold Spring Harbor symp quant biol 42 (1978) 301.

59. Germond, J E, Hirt, B, Oudet, P, Gross-Bellard, M \& Chambon, P, Proc natl acad sci US 72 (1975) 1843.

60. Griffith, J D \& Christiansen, G, Cold Spring Harbor symp quant biol 42 (1978) 215.

61. Favre, M, Breitburd, F, Croissant, O \& Orth, G, J virol 21 (1977) 1205.

62. Stüber, D \& Bujard, H, Mol gen genet 154 (1978) 299.

63. Aloni, Y, Bratosin, S, Dahr, R, Laub, O, Horowitz, M \& Khoury, G, Cold Spring Harbor symp quant biol 42 (1978) 559.

64. Aloni, Y \& Attardi, G, J mol biol 70 (1972) 363.

65. Albring, M, Griffith, J \& Attardi, G, Proc natl acad sci US 74 (1977) 1348.

66. Scheer, U, Franke, W W, Trendelenburg, M F \& Spring, H, J cell sci 22 (1976) 503.

Received January 5, 1979

Accepted March 23, 1979 